\title{
Psychological Features of Victim Behavior of Minors
}

\author{
Alma Taurbekovna Akazhanova ${ }^{1} \&$ Madina Kadyrovna Kurbanaliyeva ${ }^{1}$ \\ ${ }^{1}$ Kazakh National Pedagogical Univercity named after Abai, Almaty, Kazakhstan \\ Correspondence: Alma Taurbekovna Akazhanova, Kazakh National Pedagogical Univercity named after Abai, \\ Dostyk avenue, 13, 050010, Almaty, Kazakhstan. E-mail: alma.akazhan@mail.ru
}

Received: January 31, 2015 Accepted: February 25, 2015 Online Published: May 15, 2015

doi:10.5539/ass.v11n15p239 URL: http://dx.doi.org/10.5539/ass.v11n15p239

\begin{abstract}
The article deals with the psychological characteristics of minors' victim behavior that led to the different offenses. Victimization is understood as a set of properties of the person, specified by the complex of social, psychological and biophysical conditions, conducive to the subject's maladaptive style of response, resulting in damage to his physical or emotional-mental health. It is proposed victimological classification of the main groups of crimes committed by minors and its causes. The results of psychological support of colonies' residents and victimological circumstances of their victim behavior before their isolation from society were described.
\end{abstract}

Keywords: victim behavior, victims of crime, psychological support, minors, types of victims, rape, victims

\section{Introduction}

In recent years, psychological and criminological researches have started to pay more attention to the role of the victim in the solving and investigation of crimes. Victimology, as one of the important directions in criminology, studies the identity of the victim, his connection and relationships with criminal, features of the victim's behavior in the incriminated situation. Important place in the victimization studies is assigned to the role of the victim in the genesis of the crime, his interpersonal relations and relations with the offender.

The victimology became separate research area relatively recently, since 1947. The idea of the role of the victim in the mechanism of committing a crime is not new, it was reflected in the numerous legal and literary works and other sources since ancient times. In late XIX, early XX centuries the subject of victims were clearly observed in the writings of not only writers, but also lawyers, psychologists and criminologists. Origination of victimology associated with the name of the German scientist Hans von Genting.

In recent years, the problem of violence exposed the deep interdisciplinary analysis related to the research of culture of violence in general; tracking socio-political, cultural, psychological and biological factors contributing to the perpetuation of violence and its transmission from generation to generation. It becomes necessary to consider the second side of this process, the victim behavior of the victim.

L. V. Frank considers "victim behavior" through the category of victimization, emphasizing that all types of victimization exist in two forms: potential and realized. According to scientist, "victimization is person's potential or actual ability to individually or collectively become a victim of socially dangerous manifestations" (Frank, 1968).

V. I. Polubinsky concludes that "in determining victimization of a particular person, it shouldn't be about his increased ability to become a victim, but only about one that is directly connected with any personality characteristics and behavior of the victim or his specific relationship with offender" (Polybinsky, 1979).

H.J. Schneider in his book "Criminology" gives the following statement of H. Hentig regarding the participation of victim in the initiation and implementation of tort: "Crime is an individual psychopathological phenomenon, the victim of a crime should not be considered as passive object, because he is an active subject of criminalization" (Schneider, 1994). Hans von Hentig in his work "The Criminal and His Victim" suggested the idea of existence of dependencies between certain categories of crminals and victims of a certain type. In this work, the author "comprehensively showed how even the victim's behavior can explain one or another criminal act. The latter does not raise any doubts in relation to many cases of sexual crimes, obtaining money under false pretenses, and even murder and rape" (Frank, 1977). 
At the present stage the study of the psychological aspects of victim behavior is carried out on two main levels: as a social phenomenon and as an individual psychological characteristic of a person with his victimological activity.

\section{The Main Part}

Interpretation of the causes of victim behavior should be connected to the understanding of the nature of this complex multifactorial socio-psychological phenomenon. Its study requires modern ideas about the systematical probabilistic processes. M. I. Enikeev states that the essence of each behavioral act is determined by its place in the overall structure of person's behavior (Enikeev, 2001). In the process of individual development, behavioral systems are transformed into a complex set of individual behavioral strategies, forming a behavioral type of personality. The behavior in this case is determined and naturally caused by system of its generating factors.

One of the indicators of socio-demographic characteristics of the person is his age. This is the period of human development with certain changes in the physical and mental processes, dependent to special laws in their flow. As L. V. Frank noted, that "the basic number of criminals and victims of crime among minors are adolescents. During this period, the teenager has to solve a number of difficult problems associated with the biological processes of growing up, moral formation of his personality, the desire to get rid of adult assessment, career choice, relationships with peers of the same and opposite sex" (Frank, 1977). Of course, the crimes involve moral characteristics of personality, which reached anti-social level. In this connection, it can be concluded that most of the manifestations of victim behavior occurs due to the peculiarities of the age of minors: curiosity, credulity, easily suggestibility, naivety, inadequate response to rapidly changing circumstances due to incompleteness of their moral formation, the backlog of mental development from physical development, helpless state as a result of alcohol and drug condition, the prevalence of excitation of the process of inhibition, and sometimes even physical weakness of a teenager, conducive to become a victim of crime.

B. Weinhold and J. Weinhold define victimization as a mental disorder, which is caused by the incompleteness of one of the most important stages of development in early childhood - the stage of establishing psychological autonomy (Weinhold \& Weinhold, 2005).

Exploring victimization issues of serious aggressive-violent crimes, the Kazakhstani scholar-lawyer N. K. Kotova made a number of assumptions about the general model of the initial stage victimization:

1. By way of life an individual can (consciously or unconsciously) create objective and subjective conditions for the criminalization, favor in the commission of the crimes against himself. Standing out in social terms or isolating from society, ignoring reasonable precautions, exposing themselves to the risk associated with their own behavior, the individual in victimogenic situation usually turns into a victim.

2. Showing their asocial or antisocial mechanism, the individual is able to induce the criminal to subjectively justify his conduct and thus psychologically facilitate its commission. In such situation, there is a symbolic interaction, in which the offender distortedly interprets the behavior future victim.

3. Deviant behavior, belonging to a subculture of violence or other forms of deviant societies is often the common roots of both victimization and criminalization (Kotova, 2001).

Researches on victim behavior show that the harm to the victim can occur not only as a result of careless actions, but also as an incorrect assessment of the situation arising out of the victim behavior.

From this perspective, we tried to group the crime by the following victimological features:

1. The crimes in which the victim is passive and exhibits some personal qualities, disposing the offender to commit those or other illegal activities. For example, from the practice of cases of the City Court of Almaty: "The defendant N. met a minor B. on the street, asked to hold her up the house. Along the way, he led her into the garden, where he performed sexual intercourse with her. Then brought her to his house and re-entered into a sexual intercourse. The victim B. had an opportunity to run away from the N., but that she did not do it. Only the next day, under pressure from her mother, she informed the law enforcement agencies" (Akazhanova, 2011). The victim was described as underachieving student who repeatedly remained second year, regularly missed classes and didn't had a hobby. All her spare time she spent on the streets, in the park, making dubious acquaintances. Passivity on the part of the victim as the resolution of sexual intercourse mislead a rapist, and he has the confidence that the behavior is adequately reflected in the mind of the perpetrator and influences the formation of his mental attitude to action.

2. Crimes resulting conflict relations between the offender and the victim at the crime situations. The victims are often underage girls who established acquaintance with the rapists before they committed crimes. Provoking a 
criminal act or facilitate its commission promotes obscenity and indecent actions, joint drinking of alcoholic beverages, as well as informing the offender about the sexual availability of the victim.

3. The crimes in the commission of which the victim is in a state of dependence on the offender, physical or emotional abuse of family members, engaging in alcoholism of young children. For example, a 16-year-old M. (v. Zhaugashty, colony 155/4) serving a sentence for the murder of her stepfather, who systematically subjected her to sexual violence (Akazhanova, 2011).

4. The crimes committed at the request or with the consent of the victim (the murder of a person at his request and under the influence of compassion for him). For example, an illegal abortion with the consent of the victim. These types of criminal activities occur among adolescents.

5. Crimeswith complex (mixed) victimization character. It is the involvement in gang fights with tragic consequences, traffic crimes, etc. (Akazhanova, 2011).

Psychological support of underage inmates of the colony LA-155/4, LA-155/6 shows that the crime was preceded by lengthy conflict relations between the future victim (usually fathers or stepfathers, relatives) and convicted (Akazhanova, 2011). Teens involved in a sexual relationship with a family member, understand that the disclosure of sexual abuse will lead to family breakdown and eventual imprisonment of sex offender. Therefore, under the outward calmness of a minor there may be hiding a difficult experience. In some circumstances, disapproved actions were caused by a reaction to insults, beatings, threats from relatives and friends. Experience shows that in many cases, in such families there was a cult of violence, immorality, disrespect, rudeness, cynicism, cruelty, which caused hatred of children to the perpetrators who created the intolerable situation that led to the formation of negative qualities in adolescents. With the ongoing physical and mental development, teenagers experience great excitement and confusion. Requiring from parents more freedom, they are not able to live independently. Their behavior is fickle and inconstant.

Minors often do not think about the social and legal consequences of their actions. As V. Y. Rybalskaya notes, "minors in $2 / 3$ of studied cases of robbery and looting, less than in $1 / 3$ cases of disorderly conduct, in each third case of rape, and in every 10th case of the murder, used helplessness of the victim caused by the strong drunkenness, disease, young age". A significant number of young people dating are random and promiscuous. In recent years, with the occurrence of new car models there's an opportunity to "ride with the wind". This leads to solitude with new friends, drinking, creating a situation that leads to rape (Akazhanova, 2013).

Studies conducted by a number of scientists have confirmed the fact that victims of sexual offenses in many cases with their immoral behavior contributed to the commission of such acts, or they had "set" of certain qualities that emerged at favorable rape circumstances. Therefore, at first sight causing confusion fact that $56 \%$ of minor victims themselves contributed to the commission of rape, seems quite plausible, since more than half of them had a sexual life before committed intercourse. For many victims, this fact is not accidental, and figuratively speaking, prepared by their behavior and personal characteristics, education and living conditions of life. In terms of victimology the age is an indicator of the socio-demographic characteristics as well as socio-psychological characteristics of the individual.

Based on the degree of victimization, the following types of victims are distinguished:

1. A victim with high quality of risk is characterized by social and moral deformity. Violent crimes are often committed in deviant environment. Motives for such crimes can be selfish, hooliganism, revenge and etc ., but in any case they are determined by the specifics of interpersonal relationships. Alcoholism, drug addiction, prostitution, homosexuality, belonging to a criminal environment and etc. increase the potential risk of becoming a victim of violence.

2. A victim with increased quality of risk, social status of whom includes increased risk of being attacked. These include: justice employees, bankers, regulatory authorities and others people who have professional victimization, meaning capable of attracting the attention of the criminal with their own special aesthetic appearance and manners, as well as the mentally ill and people with psychopathological disorders.

3. A victim with little quality risk lives in normal conditions and risk factors that do not exhibit specific personality and behavioral characteristics inherent to the victims of high and increased degree of victimization.

4. An eventual (random) victim. They are victims of terrorism, murder or causing serious harm by particularly dangerous way the commission of which affected third parties.

Based on the nature and severity of personality traits that determine individual victimization, there are several types of victims: 
- Universal type. This type includes persons with strongly marked personality traits that determine their high potential vulnerability to various types of crime. They are victimization predispositions owners, the implementation of actions that are possible in a variety of criminogenic situations. The victims of this type can be characterized by typical for their activity victim behavior and passiveness.

- Selective type. This type includes those with high vulnerability to certain types of victims, taking into account their subjective and objective characteristics. Classification of the victims on the socio-demographic characteristics:

- By sex;

- Age;

- Their role status;

- Depending on their relationship to the criminal;

- Depending on the harm caused;

- On moral and psychological characteristics;

- By type and frequency of the harm caused;

- Depending on the severity of the crime;

- According to the degree of "guilt";

- The nature of their behavior (Akazhanova, 2011).

Many foreign authors emphasize the important health, social and criminal aspects of child abuse and the formation of their "cycle of violence" in the form of a transfer of an aggressive pattern of behavior from generation to generation, and the existence of a direct correlation between the severity of the punishment and the degree of aggressiveness. Victims of violence often themselves become aggressors and commit serious criminal acts including murder. That is why the problem of violence and cruelty against children is recognized as priority in the world, which is enshrined in the International Convention on the Rights of the Child (1989). It has acquired particular relevance in our country due to the increasing number of children - social orphans, who are exposed to violence within the family and outside of it (Akazhanova, 2011).

Russian researchers of victimology V. S. Minskaya, G. I. Chechel expresses their point of view, which is interesting from the standpoint of psychology: "It is possible that the sexual life of minors and young unmarried victims before the rape is not a sign of moral depravity. But in certain circumstances and with combination of other qualities (inaudibility in choosing friends, sexual intercourse with different men or alcohol abuse, etc.) or with a bad reputation, considered property of the person certainly can become the criminogenic factor" (Minskaya \& Chechel, 1988).

\section{Conclusion}

Young people, especially teenagers, in contrast to older people choose for themselves acceptable, so-called modern forms of communication, and not always scrupulously observe many conventions of mutual behavior of the sexes, characteristic and accounted among adults. Under the influence of life experience, behaviors of adults are restrained, while adolescents are more impulsive. Therefore, knowing the age qualities of minor victims is important for the development of preventive measures of victimization character. In this regard, the activities of juvenile justice staff can help to overcome the difficulties in working with children and adolescents with victim behavior. Preventive measures for the study of victimization aspects of juvenile crime will allow to change the situation, and establishing the degree of probability of being a victim of crime and the determination of its type will facilitate the activities of the relevant bodies on finding potential victims and holding with them individual preventive work on the formation of positive traits and personality qualities.

\section{References}

Akazhanova, A. T. (2011). Psychology of deviant behavior of minors: Theory and Practice. Almaty: Securities.

Akazhanova, A. T. (2013). Legal psychology: Textbook. Almaty: Nurpress.

Enikeev, M. I. (2011). Legal psychology. Moscow: Norma.

Frank, L. V. (1968). On the classification of victims in order to victimization studies. Dushanbe.

Frank, L. V. (1977). Victimology and victimization. Dushanbe.

Kotova, N. K. (2001). Victimization issues of criminal aggression. Astana: RK Institute of Law. 
Minskaya, V. S., \& Chechel, G. I. (1988). Victimization factors and the mechanism of criminal behavior. Irkutsk: Irkut University Press.

Polubinsky, V. I. (1979). Legal basis of the doctrine of crime victim. Gorky.

Schneider, H. J. (1994). Criminology. Moscow: Progress.

Weinhold, B., \& Weinnhold, J. (2005). Breaking free of the Co-dependency Trap. Moscow: Class.

\section{Copyrights}

Copyright for this article is retained by the author(s), with first publication rights granted to the journal.

This is an open-access article distributed under the terms and conditions of the Creative Commons Attribution license (http://creativecommons.org/licenses/by/3.0/). 